\title{
Family Involvement and Firm Governance: In the View of Socioemotional Wealth Protection
}

\author{
Zhenyu Yuan1, Xueliang Han1 ${ }^{*}$, Yilin Zheng2 \\ ${ }^{1}$ Management School, Jinan University, Guangzhou, China \\ ${ }^{2}$ Nan Yang Normal University, Nan Yang, China \\ Email: ${ }^{*}$ hxlmervyn@hotmail.com
}

Received 30 September 2015; accepted 24 October 2015; published 27 October 2015

Copyright (C) 2015 by authors and Scientific Research Publishing Inc.

This work is licensed under the Creative Commons Attribution International License (CC BY). http://creativecommons.org/licenses/by/4.0/

(c) $\underset{\mathrm{EY}}{\mathrm{EP}}$ Open Access

\begin{abstract}
Family business is one of the things in the past, also is the existing way, the model of the future. Based on the 1420 private companies listed in China for 7 years (2006-2012), data statistical analysis found that with the increasing of the year, two rights separation degree of private enterprises were falling. As the change of the institutional environment, involved in the enterprise internal members of the family are increasing, and the source is also diversified. Listed on the mainland China for 717 family enterprises 7 years (2006-2012), the data of empirical test showed that the family members involved in the enterprise are advantageous to the family firm social emotional wealth preservation; the relationship of core family and family enterprise social emotional wealth behavior had a direct relationship. The improvement of the external institutional environment also be advantageous to the family enterprise social emotional wealth preservation, and the external environment will also be able to change influence of the family members involved in the enterprise to family enterprise social emotional wealth preservation behavior. The outbreak of the financial crisis eases the contradiction between the members of the family and the common crisis awareness, which shows the relationship between brothers and relatives and friends with the core family relationship (marriage) family members for the preservation of the family enterprise social emotional wealth which make greater contribution than the second direct generation.
\end{abstract}

\section{Keywords}

Family Involvement, Social Emotional Wealth, Ownership Concentration, Two Rights Separation

\footnotetext{
"Corresponding author.
}

How to cite this paper: Yuan, Z.Y., Han, X.L. and Zheng, Y.L. (2015) Family Involvement and Firm Governance: In the View of Socioemotional Wealth Protection. Open Journal of Business and Management, 3, 453-464. 


\section{Introduction}

Since the kick-off of 3rd Plenary Session of 11th Central Committee of the Communist Party of China (CPC) in 1978, along with the "Reform and Opening Up” policy, the potential of marketability of China's economic system has been more and more obvious, and the potential of private economy has been released as well. Benefited from policy superiority, private firms in China have become the main component of national economy. Recently, the 3rd Plenary Session of 18th CPC Central Committee was held in Nov. 2013, not only reiterated the importance of market economy in China, but also strengthened the confidence of China's private entrepreneurs. What should be mentioned is that the divergence between ownership and control rights had not been impaired by the market economy reform, but had been reinforced by the family involvement. Therefore, this paper counted the proportion of the actual control-rights and the proportion of the actual ownership based on 7 (2006-2012) years' data of 1420 private-listed firms in China from the database of China Stock Market Accounting Research (CSMAR). The fluctuations of the two proportions could be seen in Figure 1, which also showed the fitting curves of the two lines from 2006 to 2012.

Figure 1 demonstrates that from 2006 to 2012, both the proportion of the actual control-rights and the proportion of the actual ownership went up. In fact, the data confirmed that the divergence of ownership and controlrights declined $0.7 \%$ from 2006 to 2012. Although this change might have many secondary causes, the principal social cause remained as the most significant and relevant one. Firstly, after family members were embedded into the family enterprises, the divergence between ownership and control-rights would be more than likely undermined. (In reality, according to Chinese Family Business Report: in 2011, 85.4\% private firms were family firms). In addition, while the market economy reform liberated the development potential for private firms, it also intensified their sense of crisis at the same time, especially private family firms, which would eventually push family members to participate in their own family business. Therefore, in the following research, this paper would unveil. Which family members had participated in the private firms? What effects had been brought by family involvement to firm governance? Could the external environment change bring any impacts on the family members' behaviours?

\section{Theory Analysis and Hypothesis}

\subsection{Family Firm Research and Family Involvement Motivation}

The phenomenon of terminology overlap and empirical results contradiction is common in family firm researches [1]. Asaba, S. (2012) argues that the family firms can reduce the agent conflicts which can be seen in

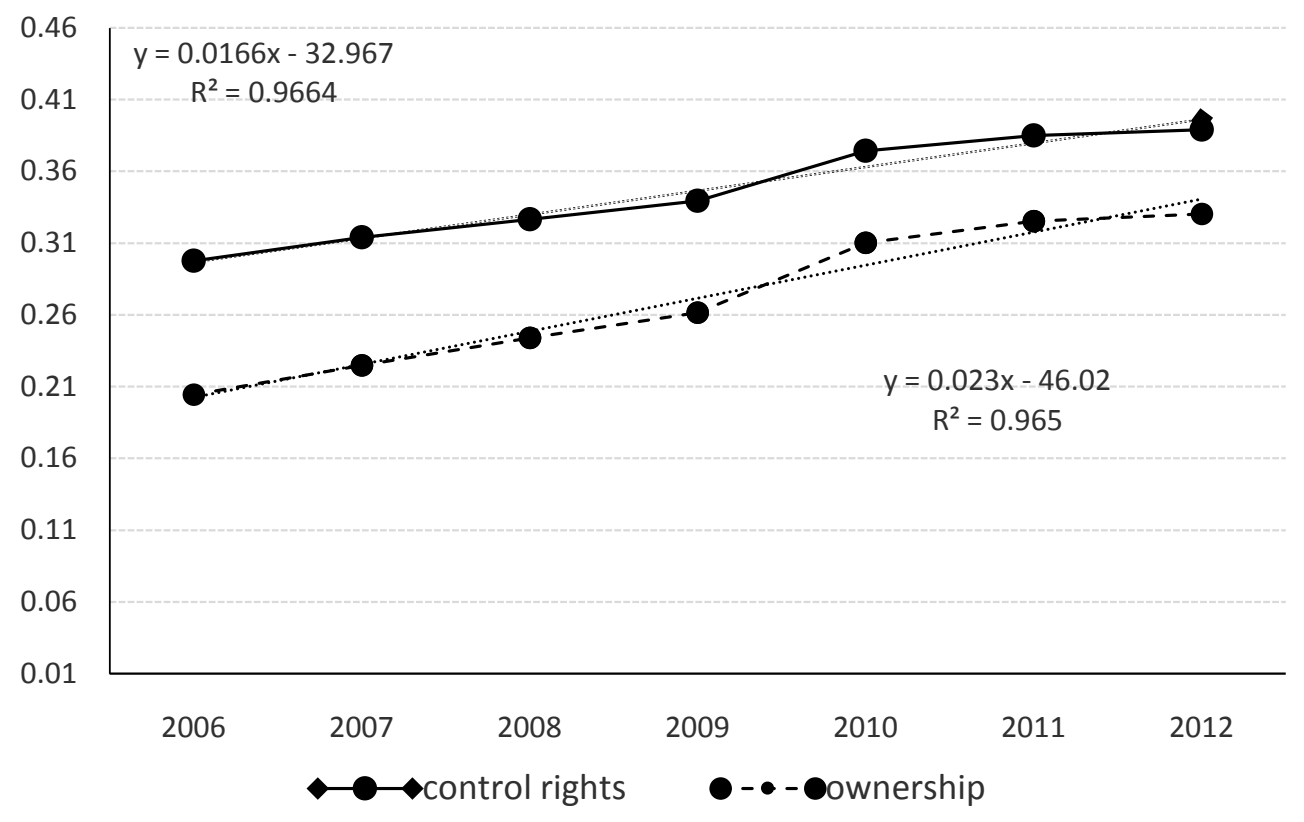

Figure 1. The proportion of the actual control rights and the proportion of the actual ownership. 
non-family firms constantly. If the firm can integrate the control rights and ownership, it will cut down the costs and establish competitive advantages. Give tit for tat, Wasserman, N. (2006) argues that there is "PrincipalPrincipal" agency problems in family firms. The person who dominates the firm might take advantages of information asymmetry in order to invade and occupy other owners' benefits. From the perspective of embeddedness, Le Breton-Miller, I., Miller, D. \& Lester, R. H. [2] reconciled the two contrary arguments. However, there are still certain unsolved concerns to explain the firms' behaviour and family members' action. Here comes the question, why more and more family members became employees of family firms? Under situation like this, the socioemotional wealth theory reveals its vitality. According to the recent studies, the socioemotional wealth should include the family's power and effects in the firm, the needs of family members' ascription sense and intimation, the continuation of family values, the altruism among family members, the family's social capital and the family firm's heritage at least [3]. When conducting the strategic planning, family firms should take socioemotional wealth into consideration as a key component. What is more, if the family loses the control-rights, their socioemotional wealth would be challenged by nonfamily members. Indeed, comparing to the control-right, the ownership is a basic power. Thus, the socioemotional wealth is linked not only to the control-rights but also to the ownership. Therefore, another question, is it the ownership or the control-rights, would influence the socioemotional wealth eventually? The loss of socioemotional wealth will lead to the desalination affection among family members, the drop of family's social status, disappointment against members' original expectations, etc. As a result, we consider that protecting the socioemotional wealth is not only the ultimate aim for family members, but also an important strategic action for family enterprise operation.

\subsection{Family Involvement and Socioemotional Wealth}

Following the step of Le Breton-Miller, L. \& Miller, D. [2], we also believe that the socioemotional wealth affects the whole operation process of family enterprise. In their research, as the family business grows, the ownership and control-rights will be shifted from the individual founder to the founder's family, and finally dominated by "Cousin Consortia". Exactly as they pointed out that family involvement is the root of transformation of ownership and control-rights. Obviously, we do find evidence from the 1,420 private-listed firms in China. Based on the data from CSMAR, this paper classifies the family members embedded into the family firms according to different types of GUANXI (literally meaning relationship), which can be seen from Figure 2.

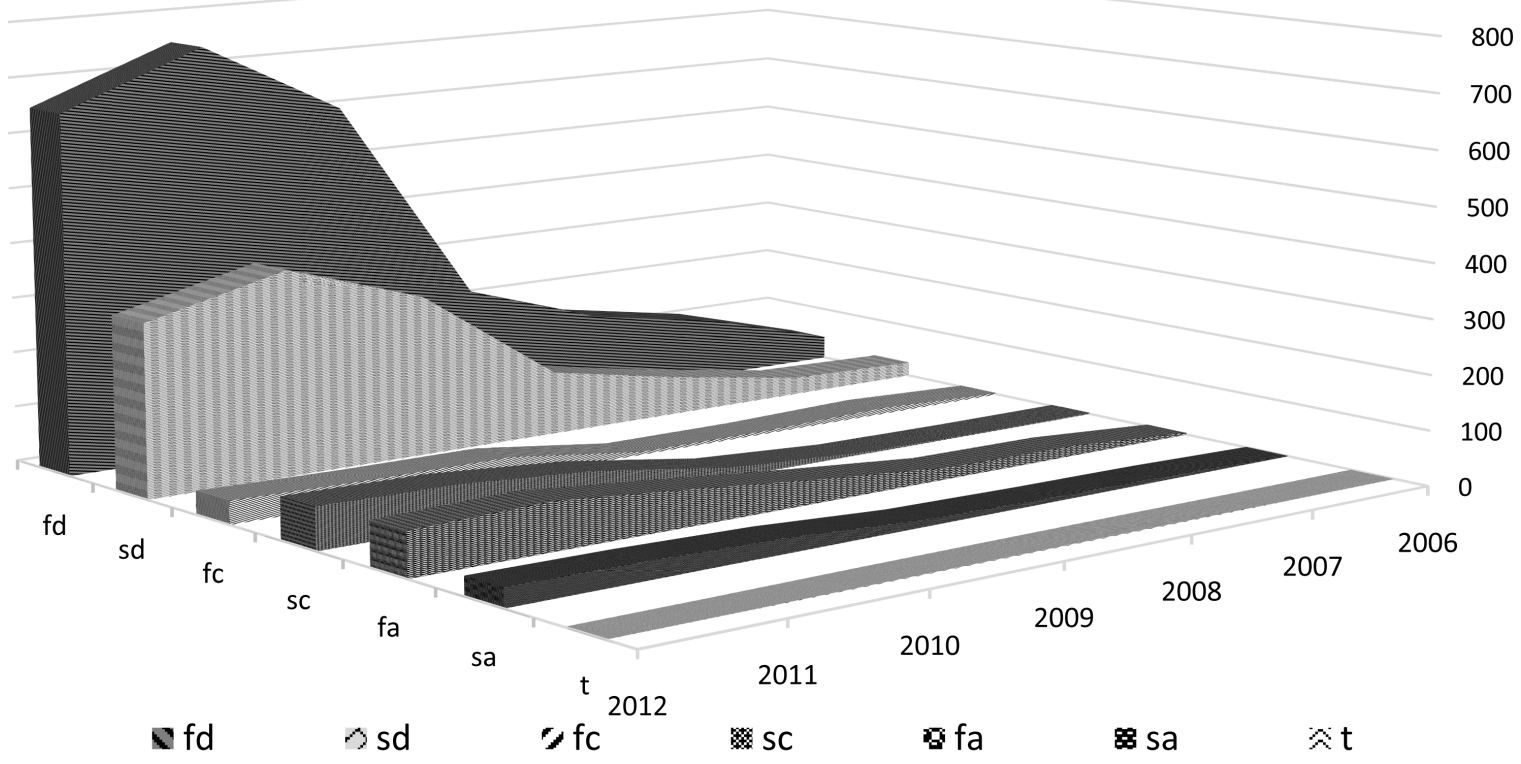

Figure 2. The FI of Chinese private-listed firms (2006-2012). Fd: the first generation of direct folks; sd: the second generation of direct folks; fc: the first generation of collateral series; sc: the second generation of collateral series; fa: the first generation of affinity; sa: the second generation of affinity; t: the third generation. The 7 types of relationship are distinguished by 103 words which can represent the Chinese GUANXI. These words are cited carefully by us from the CSMAR. 
Figure 2 illustrates that of all the family members involved in the business, the first generation of direct folks occupies the most seats, and then followed by the second generation, the first generation of affinity and the first generation of collateral series. Only few members from the third generation participate in the business. Actually, when the firm was established, only a few people from the core family were embedded in the firm. With the progress of the firm, the status of founders has been confirmed. Then, the board is elected to meet the request of legitimacy, especially when the firm goes public. As the family business expands, collisions between the first generation and the second generation intensified, the conflicts among different relatives aggravated at the same time. Thus how to manage the large family enterprise has become a thorny issue. On one hand, in order to balance the interests, ease conflicts, and maintain harmonious relationship, people outside the core family are needed to add some diversity to the Board, in the form of specialized committee. On the other hand, along with the family enterprise expansion, the impact and the image will appear particularly eye-catching to the public, pressure from social responsibility will rise as well. As a result, nonfamily members are called to be introduced to the board. We name them as "conciliators". However, the "conciliators" do not have economic priorities but only provide cognate assistance. Based on the above theoretical analysis, we propose:

Hypothesis 1a: family involvement is positive with socioemotional wealth protection;

Hypothesis 1b: Different family member performance distinct behaviors in socioemotional wealth protection.

\subsection{External Environment Change and Family Involvement}

The quality of external environment reflects the degree of system risk in business. Here, we focus the external environment change on institutional environment. Based on Agency Cost (AC) Theory and Resource-Based View (RBV), the previous studies discuss that: there is an alternative relationship between institutional environment and family involvement. In the perspective of AC, the better the institutional environment, the lower the family involvement. This phenomenon is explained by RBV as the following: the decline is caused by advantages of social capital, which has been replaced by business resources during the process of market reform. La Porta, R., et al. [4] reasons out that if the change of institutional environment is not conducive to protect investors, the number of family firm will be down gradually. Considering the theory of the socioemotional wealth, the family firm's attitude and behavior depends on the nature of the risk in the future [5]. After all, if the risk happens later, the whole family will be affected [6]. They may lose their properties agglomerating all of the families’ painstaking efforts. In contrast, some studies have questioned the argument of AC and RBV. They find that during the period of economic transition, institutional environment improvement and economic development attract more family members [7]. Here, we have Figure 2 in the following to support Chen's point, which shows a positive correlation between institutional environment improvement and family involvement. Besides, there is a neutral statement proposed by Miller, D. et al. [2]: the changes of external environment change play an important role as regulation mechanism in adjusting the effects of family involvement in firm governance. Benefited by the economic reform in China, the external environment change has kept a staggering growth trend in the past 35 years. Therefore, we propose the following:

Hypothesis 2: The improving of the external environment change is positive with socioemotional wealth protection;

Hypothesis 3: The change of the external environment change could adjust the behaviors of family members in socioemotional wealth protection.

\section{Data and Method}

\subsection{Data Collection}

It is easy to define a firm, however it is complicated to define a firm as a family firm. A family firm may become a nonfamily firm referring to stringent standards. In this paper, we define family firm under a loose concept, if the firm is controlled by family or natural person, it could be defined as a family firm. Based on CSMAR, we collected 717 firms that meet this notion as of December 31st, 2009.

\subsection{Measurement}

\subsubsection{Family Involvement}

How to measure family involvement, especially the degrees of family involvement? If only one person is em- 
bedded in the firm that can make family involvement, all of our samples are family involvement firms. We jump out of the limitation of previous studies, and attempt to distinguish the different degrees of family involvement among family firms. Luckily, we conceive this variable through 103 words which represent the Chinese GUANXI. Firstly, we distinguish four basic types of GUANXI: couples (gf), parentage (gs), brothers (kf) and relatives (ks).

Among which, the "g" represents the "direct folks"; the " $k$ " represents the "collateral series"; the " $p$ " represents the first generation; and the "s" represents the "second generation". We must take further clarification that the "ks" also includes the relationship of affinity. What should be pointed out is that we do not consider the third generation in our empirical study (because there are only 3 observations in our sample).

Then we define the "gf" as the core GUANXI, which correlates with other ones. Thus, 8 types of GUANXI are presented to us: "gf”, "gfkf”, "gfgs”, "gfgskf”, "gfks”, "gfkfks”, "gfgsks” and "gfgskfks”. In the next section, we are trying to tie up each GUANXI with a different family involvement utilizing dummy variables.

\subsubsection{Family Firm Governance}

In the theoretical analysis, we consider socioemotional wealth protection as the motivation of family involvement, and as result family involvement impacts family firm governance. In previous studies, the family business governance measurement mainly focuses on the internal structure of the Board and team structure of top management. Common measurement indicators include the size of the Board, independence of Board, CEO Duality, etc [8]. In our study, we consider three data: the sum of squares of 10 top circulating stock shareholders shareholding ratio (herfindahl_10), the sum of squares of different strategic shareholders shareholding ratio (shrhfdm) and the separation of the ownership and control-rights (vc). These data can reflect the comprehensive governance level of family firms, and are closely related to socioemotional wealth. Mean while we acquiesce that the higher the herfindahl_10 and the shrhfdm, the lower the vc, and the better for socioemotional wealth preservation.

\subsubsection{External Environment Change}

In the past research, external environment change is usually reflected by Fan Gang’s (Chinese: 樊刚, one of China's most prominent economists) edition of market index. Notably, many survey based indicators in this index are not being reinvestigated when confronting new situations, thus making the index lose its original meaning of measurement. Meanwhile, due to GDP data adjustment by National Bureau of Statistics and some incomplete data, the reliability and representativeness of Fan's edition of market index is debatable. Considering that the data quality may influence the research, we adopt "local family firms' operating income in current year" and "all local firms' operating income in current year" to construct a new index, namely, the privatization process, or provrevenue. In the empirical test, we utilize this index to reflect external environment change. Additionally, we define the time before 2008 is the pre-crisis period (PC), the time from 2008 to 2009 is the crisis period (IC), the time after 2009 is the later period (LC) and the time from 2006 to 2012 is the Research Interval (P).

\subsubsection{Control Variables}

When the family business performance is beyond expectations, the owners are more likely to think about business sustainability [9]. Based on this fact, the variables representing business performance are named as control variables. In this paper, control variables include: the performance (t40401); the listed age of the firm (age) and its square (age_2); the size of the firm (empnum—-the number of the employees) and the industry (indcd_c/ indcd_m/indcd_j/indcd_o).

The statistics of the variables (which are used to test the hypotheses) and the correlations between each other can been seen from Table 1.

\subsection{Method}

Based on 7 years panel data, we choose the random effects models. There are some legitimate reasons what we have squared up. Firstly, the panel data includes the larger information than cross-sectional data and time-series data. It can make up for the bias of omitted variables which often occur in instrumental variables regression. Secondly, the individual should be treated as a random, generally [10]. Last but not least, compared to the number of the firms (717), the number of the years (7) is tinny. In order to guarantee the freedom of variables, it is 
Table 1. The Descriptive statistics and correlations among the main variables.

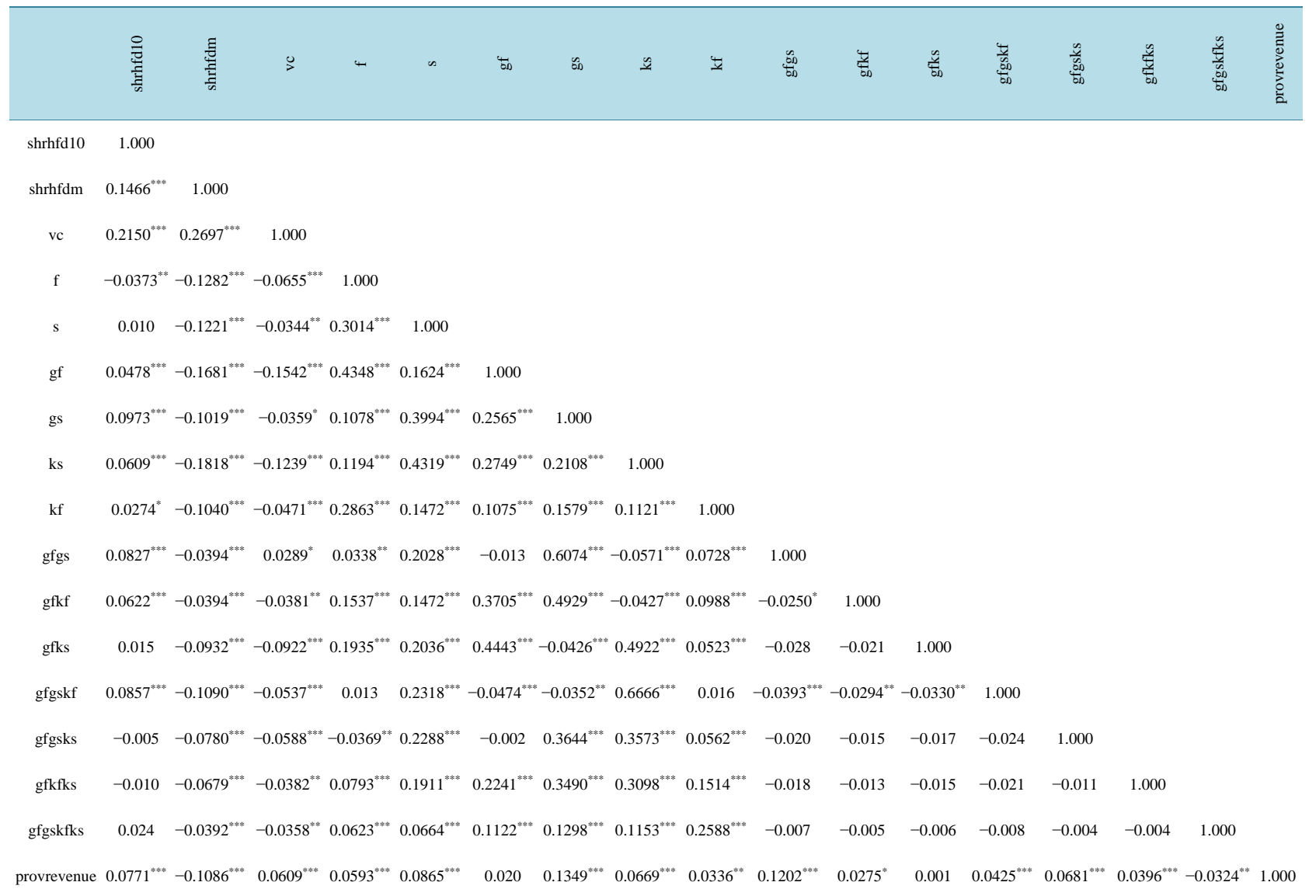

${ }^{*} p<0.1 ;{ }^{* *} p<0.05 ;{ }^{* * *} p<0.01$. Note: Table 1 shows the numbers/the mean values/the standard deviations/the min values and the max values of each main variables (which are used to test the hypotheses), integrating with the correlations between each other.

better to avoid choosing the fixed effects model. We also take the Breusch-Pagan Test after each regression in the process of the empirical research, and the good side is that the results of the B-P tests support our choice.

\subsection{Models}

In order to examine the Hypothesis $1 \boldsymbol{a}$ and Hypothesis $\mathbf{1 b}$, we build model 1:

$$
\text { sew }_{i t}=\alpha_{0}+\beta_{i t} \text { kinship }+\varepsilon_{i t}+\mu_{i}
$$

For Hypothesis 2, we build model 2:

$$
\text { sew }_{i t}=\alpha_{0}+\beta_{i t} \text { kinship }+\gamma_{i t} \text { provrevenue }+\delta_{i t} \text { kinship } * \text { provrevenue }+\varepsilon_{i t}+\mu_{i}
$$

For Hypothesis 3, we take the interaction variables into the models and regress the model 1 and model 2 under the condition of controlling the external environment change (crisis).

where,

$$
\begin{aligned}
\text { kinship }_{i t}=\left\{\begin{array}{l}
g f_{i t}, g s_{i t}, k f_{i t}, k s_{i t} \\
g f_{i t}, g f g s_{i t}, g f k f_{i t}, g f k s_{i t}, g f g s k f_{i t}, g f g s k s_{i t}, g f k f k s_{i t}, g f g s k f k s_{i t}
\end{array}\right. \\
\qquad \operatorname{sew}_{i t}=\left\{\begin{array}{l}
h r h f d 10_{i t} \\
s h r h f d m_{i t} \\
v c_{i t}
\end{array}\right.
\end{aligned}
$$

$\alpha_{0}$-Intercept; $\left(\varepsilon_{i t}+\mu_{i}\right)$-Disturbance Term; $i$-Firm; $t$-Year. 


\section{Results}

Tables 2-4 present the results of our estimation. We show three different model specifications. In (1) the regression contains the whole data, in (2) the regression only includes the data of PC and in (3) the regression merely involves the data of LC. Each regression is under the condition of subjecting to other variables. Limited by the forums, the results of control variables do not present in each table. The standard errors of each main variable are in the following. The asterisk $\left(^{*}\right)$ represents the significance of each variable: ${ }^{*} p<0.1,{ }^{* *} p<0.05,{ }^{* * *} p<0.01$. Interpretations are as follows.

Table 2. FI and firm governance.

\begin{tabular}{|c|c|c|c|c|c|c|c|c|c|c|c|c|c|c|c|c|c|c|}
\hline & (1) & (2) & (3) & (1) & (2) & (3) & (1) & (2) & (3) & (1) & (2) & (3) & (1) & (2) & (3) & (1) & (2) & (3) \\
\hline $\begin{array}{c}\text { VARIAB } \\
\text { LES }\end{array}$ & shrhfd10 & shrhfd10 & shrhfd10 & shrhfd 10 & shrhfd 10 & shrhfd10 & shrhfdm & shrhfdm & shrhfdm & shrhfdm & shrhfdm & shrhfdm & vc & vc & vc & vc & vc & vc \\
\hline gf & -0.00565 & -0.0152 & -0.00604 & -0.00666 & -0.0205 & -0.00697 & -0.0273 & -0.0548 & -0.0327 & -0.0324 & -0.074 & -0.038 & -0.45 & -1.391 & -0.506 & -0.531 & -1.876 & -0.583 \\
\hline gs & -0.00616 & -0.0129 & -0.00689 & & & & -0.0301 & -0.05 & -0.0374 & & & & -0.495 & -1.234 & -0.585 & & & \\
\hline \multirow[t]{2}{*}{$\mathrm{kf}$} & 0.00161 & -0.00565 & 0.0128 & & & & $-0.164^{* * *}$ & $-0.299^{* * *}$ & -0.0481 & & & & -0.685 & 0.0924 & -0.0828 & & & \\
\hline & -0.0105 & -0.0221 & -0.011 & & & & -0.0528 & -0.104 & -0.0623 & & & & -0.842 & -2.146 & -0.931 & & & \\
\hline \multirow[t]{2}{*}{ ks } & $0.0105^{*}$ & -0.00461 & $0.0140^{* *}$ & & & & $-0.139^{* * *}$ & $-0.102^{* *}$ & -0.0167 & & & & $-1.264^{* * *}$ & -1.175 & -0.716 & & & \\
\hline & -0.00603 & -0.0135 & -0.00669 & & & & -0.0285 & -0.0507 & -0.0354 & & & & -0.478 & -1.246 & -0.558 & & & \\
\hline \multirow[t]{2}{*}{ gfgs } & & & & 0.00851 & $-0.0299^{*}$ & 0.0101 & & & & $-0.0699^{*}$ & -0.0532 & -0.00673 & & & & 0.423 & $3.353^{*}$ & -0.681 \\
\hline & & & & -0.00775 & -0.0181 & -0.00855 & & & & -0.0393 & -0.0693 & -0.0481 & & & & -0.626 & -1.748 & -0.737 \\
\hline \multirow[t]{2}{*}{ gfkf } & & & & 0.00289 & 0.0118 & -0.001 & & & & 0.0273 & $-0.299^{* * *}$ & $0.154^{* *}$ & & & & -0.106 & 0.148 & -0.52 \\
\hline & & & & -0.0117 & -0.0276 & -0.0132 & & & & -0.0589 & -0.103 & -0.0743 & & & & -0.947 & -2.554 & -1.115 \\
\hline \multirow[t]{2}{*}{ gfks } & & & & 0.0152 & -0.00487 & 0.00711 & & & & -0.0573 & $-0.161^{*}$ & 0.0265 & & & & -0.746 & -1.212 & -1.101 \\
\hline & & & & -0.0112 & -0.0268 & -0.0128 & & & & -0.0552 & -0.0974 & -0.0695 & & & & -0.889 & -2.467 & -1.068 \\
\hline \multirow[t]{2}{*}{ gfgskf } & & & & 0.0112 & -0.00192 & $0.0141^{*}$ & & & & $-0.171^{* * *}$ & $-0.110^{*}$ & -0.000933 & & & & $-1.347^{* *}$ & 0.195 & -0.854 \\
\hline & & & & -0.00755 & -0.0167 & -0.00796 & & & & -0.0364 & -0.0651 & -0.0435 & & & & -0.601 & -1.558 & -0.669 \\
\hline gfgsks & & & & -0.0128 & -0.0299 & -0.0144 & & & & -0.0633 & -0.132 & -0.0789 & & & & -1.016 & -2.972 & -1.209 \\
\hline \multirow[t]{2}{*}{ gfkfks } & & & & 0.00444 & -0.0235 & 0.0202 & & & & -0.084 & $-0.535^{* * *}$ & 0.00269 & & & & -0.392 & -1.92 & -0.425 \\
\hline & & & & -0.0141 & -0.039 & -0.0164 & & & & -0.0723 & -0.142 & -0.0917 & & & & -1.117 & -3.597 & -1.377 \\
\hline \multirow[t]{2}{*}{ gfgskfks } & & & & 0.024 & 0 & 0.0264 & & & & -0.27 & 0 & -0.072 & & & & $-8.336^{* *}$ & 0 & -0.914 \\
\hline & & & & -0.0427 & 0 & -0.0388 & & & & -0.199 & 0 & -0.209 & & & & -3.379 & 0 & -3.239 \\
\hline \multirow[t]{2}{*}{ Constant } & $0.0937^{* * *}$ & $0.162^{* * *}$ & $0.0563^{* * *}$ & $0.0935^{* * *}$ & $0.162^{* * *}$ & $0.0577^{* * *}$ & $0.718^{* * *}$ & $0.149^{* *}$ & $0.400^{* * *}$ & $0.717^{* * * *}$ & $0.135^{*}$ & $0.400^{* * *}$ & $7.460^{* * * *}$ & $6.418^{* * *}$ & $3.177^{* *}$ & $7.459^{* * *}$ & $6.357^{* * *}$ & $3.261^{* *}$ \\
\hline & -0.0132 & -0.0209 & -0.0169 & -0.0132 & -0.0209 & -0.0169 & -0.0524 & -0.0697 & -0.0752 & -0.0525 & -0.0698 & -0.0754 & -1.047 & -1.877 & -1.332 & -1.049 & -1.875 & -1.333 \\
\hline $\mathrm{Ob}$ & 4600 & 1117 & 2138 & 4600 & 1117 & 2138 & 4575 & 1092 & 2138 & 4575 & 1092 & 2138 & 4465 & 1075 & 2082 & 4465 & 1075 & 2082 \\
\hline No.stkcd & 717 & 601 & 716 & 717 & 601 & 716 & 717 & 586 & 716 & 717 & 586 & 716 & 717 & 587 & 707 & 717 & 587 & 707 \\
\hline
\end{tabular}

${ }^{*} p<0.1 ;{ }^{* *} p<0.05 ;{ }^{* * *} p<0.01$. 
Table 3. External environment change, FI and firm governance (1).

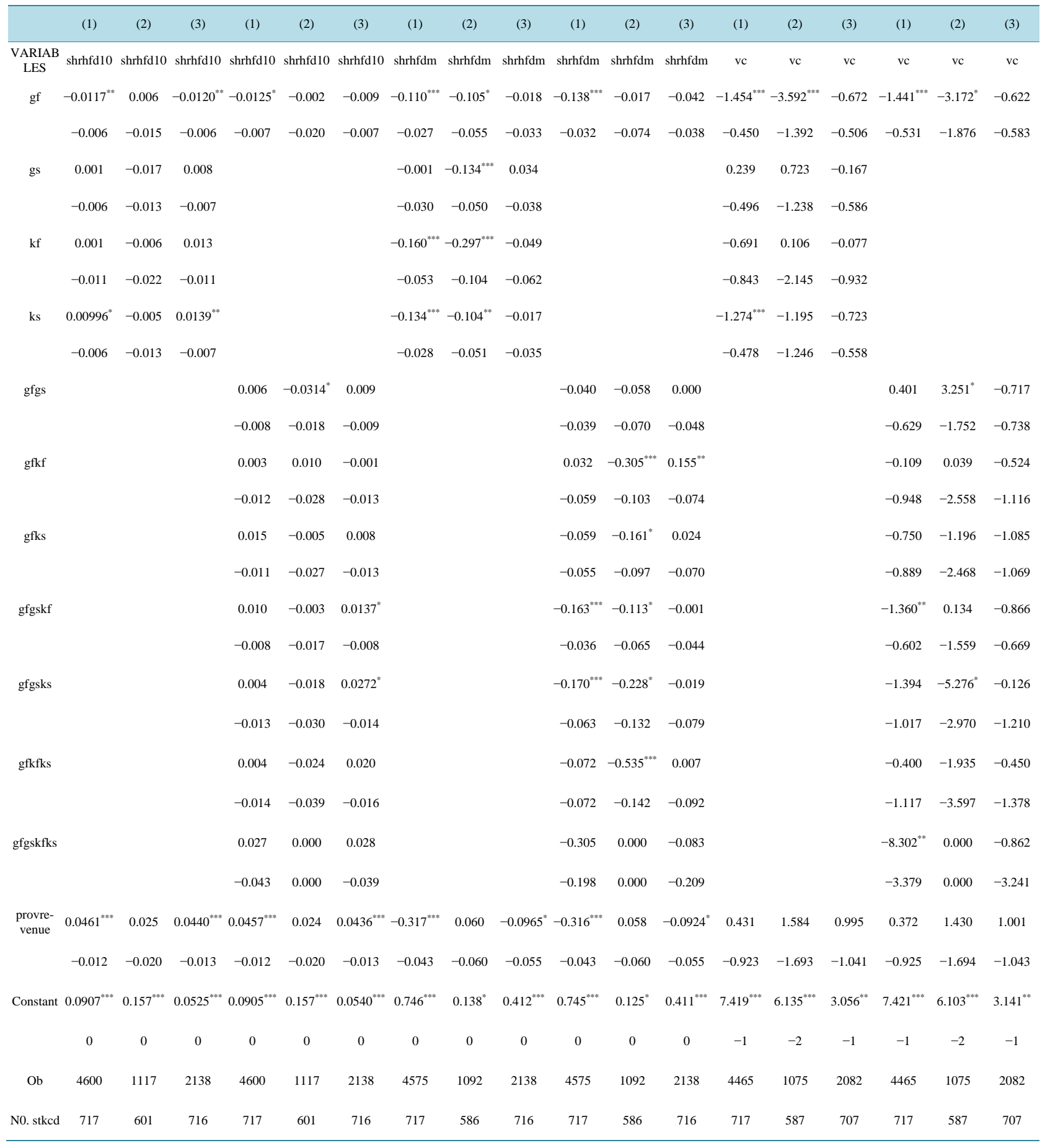

${ }^{*} p<0.1 ;{ }^{* *} p<0.05 ;{ }^{* * *} p<0.01$.

\subsection{Family Involvement and Firm Governance}

We first examine whether family involvement is positive with socioemotional wealth protection (Hypothesis 1a) and whether different family members perform distinct behaviors in socioemotional wealth protection (Hypothesis $\mathbf{1 b}$ ) at the firm governance level. The results offer some support for Hypothesis $1 \boldsymbol{a}$ and Hypothesis $\mathbf{1 b}$, as can be seen from Table 2 . 
Table 4. External environment change, family involvement and firm governance (2).

\begin{tabular}{|c|c|c|c|c|c|c|c|c|c|c|c|c|c|c|c|c|c|c|}
\hline & (1) & (2) & (3) & (1) & (2) & (3) & (1) & (2) & (3) & (1) & (2) & (3) & (1) & (2) & (3) & (1) & (2) & (3) \\
\hline VARIABLES & shrhfd10 & shrhfd10 & shrhfd10 & shrhfd 10 & shrhfd10 & shrhfd10 & shrhfdm & shrhfdm & shrhfdm & shrhfdm & shrhfdm & shrhfdm & $\mathrm{vc}$ & $\mathrm{vc}$ & $\mathrm{vc}$ & $\mathrm{vc}$ & $\mathrm{vc}$ & $\mathrm{vc}$ \\
\hline \multirow[t]{2}{*}{ gf } & $-0.0113^{* *}$ & 0.005 & $-0.0125^{* *}$ & $-0.0124^{*}$ & -0.002 & -0.011 & $-0.110^{* * *}$ & $-0.109^{*}$ & -0.020 & $-0.138^{* * *}$ & -0.024 & -0.042 & $-1.375^{* * *}$ & $-3.602^{* *}$ & -0.793 & $-1.418^{* * *}$ & -1.629 & -0.846 \\
\hline & -0.006 & -0.015 & -0.006 & -0.007 & -0.023 & -0.007 & -0.027 & -0.056 & -0.033 & -0.033 & -0.077 & -0.038 & -0.455 & -1.404 & -0.518 & -0.536 & -1.993 & -0.596 \\
\hline \multirow[t]{2}{*}{ gs } & -0.002 & -0.018 & 0.005 & & & & 0.002 & $-0.143^{* * *}$ & 0.038 & & & & 0.101 & 0.672 & -0.320 & & & \\
\hline & -0.007 & -0.013 & -0.007 & & & & -0.032 & -0.053 & -0.040 & & & & -0.527 & -1.290 & -0.616 & & & \\
\hline \multirow[t]{2}{*}{ kf } & 0.001 & -0.007 & 0.009 & & & & $-0.160^{* * *}$ & $-0.325^{* * *}$ & -0.051 & & & & -0.645 & 0.020 & -0.162 & & & \\
\hline & -0.011 & -0.022 & -0.011 & & & & -0.053 & -0.106 & -0.063 & & & & -0.847 & -2.183 & -0.955 & & & \\
\hline \multirow[t]{2}{*}{ ks } & $0.0110^{*}$ & -0.006 & $0.0147^{* *}$ & & & & $-0.136^{* * *}$ & $-0.0988^{*}$ & -0.016 & & & & $-1.314^{* * *}$ & -1.168 & -0.658 & & & \\
\hline & -0.006 & -0.014 & -0.007 & & & & -0.029 & -0.052 & -0.036 & & & & -0.481 & -1.259 & -0.568 & & & \\
\hline \multirow[t]{2}{*}{ gfgs } & & & & 0.004 & $-0.0313^{*}$ & 0.007 & & & & -0.032 & -0.075 & 0.001 & & & & 0.383 & 2.715 & -0.910 \\
\hline & & & & -0.009 & -0.018 & -0.009 & & & & -0.044 & -0.071 & -0.054 & & & & -0.701 & -1.770 & -0.806 \\
\hline \multirow[t]{2}{*}{ gfkf } & & & & 0.000 & 0.011 & -0.001 & & & & 0.031 & $-0.308^{* * *}$ & $0.154^{* *}$ & & & & -0.187 & -0.930 & -0.545 \\
\hline & & & & -0.012 & -0.029 & -0.013 & & & & -0.060 & -0.108 & -0.075 & & & & -0.974 & -2.678 & -1.122 \\
\hline \multirow[t]{2}{*}{ gfks } & & & & 0.016 & -0.017 & 0.005 & & & & -0.060 & -0.166 & 0.026 & & & & -0.780 & -3.391 & -0.753 \\
\hline & & & & -0.011 & -0.031 & -0.014 & & & & -0.055 & -0.101 & -0.071 & & & & -0.892 & -2.663 & -1.120 \\
\hline \multirow[t]{2}{*}{ gfgskf } & & & & 0.011 & -0.003 & $0.0157^{*}$ & & & & $-0.162^{* * *}$ & $-0.113^{*}$ & 0.003 & & & & $-1.352^{* *}$ & 0.063 & -0.779 \\
\hline & & & & -0.008 & -0.017 & -0.008 & & & & -0.037 & -0.067 & -0.045 & & & & -0.604 & -1.563 & -0.681 \\
\hline \multirow[t]{2}{*}{ gfgsks } & & & & 0.002 & -0.022 & $0.0324^{* *}$ & & & & $-0.170^{* * *}$ & $-0.227^{*}$ & -0.022 & & & & -1.256 & -4.766 & -0.088 \\
\hline & & & & -0.013 & -0.030 & -0.015 & & & & -0.064 & -0.133 & -0.080 & & & & -1.030 & -2.999 & -1.227 \\
\hline \multirow[t]{2}{*}{ gfkfks } & & & & 0.005 & -0.054 & $0.0370^{* *}$ & & & & -0.084 & $-0.512^{* * *}$ & 0.000 & & & & -0.607 & -1.951 & 0.179 \\
\hline & & & & -0.015 & -0.048 & -0.019 & & & & -0.076 & -0.156 & -0.107 & & & & -1.170 & -4.163 & -1.579 \\
\hline \multirow[t]{2}{*}{ gfgskfks } & & & & 0.300 & 0.000 & 0.282 & & & & -0.581 & 0.000 & -0.291 & & & & -4.602 & 0.000 & -8.576 \\
\hline & & & & -0.193 & 0.000 & -0.193 & & & & -0.690 & 0.000 & -0.763 & & & & -15.170 & 0.000 & -14.580 \\
\hline \multirow[t]{2}{*}{ provrevenue } & $0.0449^{* * *}$ & 0.023 & $0.0443^{* * * *}$ & $0.0462^{* * *}$ & 0.019 & $0.0446^{* * *}$ & $-0.317^{* * *}$ & 0.053 & $-0.0953^{*}$ & $-0.319^{* * *}$ & 0.058 & $-0.0926^{*}$ & 0.419 & 1.605 & 0.994 & 0.388 & 2.121 & 1.013 \\
\hline & -0.012 & -0.020 & -0.013 & -0.012 & -0.020 & -0.013 & -0.043 & -0.061 & -0.055 & -0.043 & -0.062 & -0.056 & -0.925 & -1.710 & -1.042 & -0.930 & -1.726 & -1.047 \\
\hline \multirow[t]{2}{*}{ gfprevrenune } & -0.028 & -0.040 & -0.023 & -0.030 & -0.103 & -0.040 & -0.022 & -0.193 & -0.046 & -0.060 & -0.043 & -0.076 & 0.059 & 0.048 & -3.789 & -0.265 & $16.71^{*}$ & $-5.392^{*}$ \\
\hline & -0.026 & -0.073 & -0.032 & -0.030 & -0.108 & -0.037 & -0.123 & -0.255 & -0.155 & -0.142 & -0.361 & -0.177 & -2.074 & -6.583 & -2.569 & -2.411 & -9.483 & -2.979 \\
\hline \multirow[t]{2}{*}{ gsprevrenune } & 0.032 & 0.013 & 0.038 & & & & -0.034 & 0.311 & -0.042 & & & & 1.655 & 2.892 & 1.731 & & & \\
\hline & -0.024 & -0.056 & -0.027 & & & & -0.117 & -0.222 & -0.145 & & & & -1.922 & -5.437 & -2.279 & & & \\
\hline \multirow[t]{2}{*}{ kfprevrenune } & -0.0467 & 0.114 & -0.0831 & & & & -0.019 & -0.270 & 0.017 & & & & 1.012 & -5.495 & -1.613 & & & \\
\hline & -0.044 & -0.100 & -0.053 & & & & -0.210 & -0.446 & -0.263 & & & & -3.630 & -9.665 & -4.309 & & & \\
\hline \multirow[t]{2}{*}{ ksprevrenune } & -0.041 & -0.063 & -0.030 & & & & 0.034 & -0.139 & -0.025 & & & & 2.014 & 0.932 & -1.061 & & & \\
\hline & -0.027 & -0.055 & -0.031 & & & & -0.127 & -0.212 & -0.161 & & & & -2.135 & -5.156 & -2.554 & & & \\
\hline \multirow[t]{2}{*}{$\begin{array}{l}\text { Gfgs- } \\
\text { prevrenune }\end{array}$} & & & & 0.010 & -0.042 & 0.019 & & & & -0.067 & 0.320 & -0.011 & & & & 0.257 & $14.63^{*}$ & 1.550 \\
\hline & & & & -0.029 & -0.077 & -0.031 & & & & -0.148 & -0.296 & -0.177 & & & & -2.355 & -7.468 & -2.687 \\
\hline
\end{tabular}




\begin{tabular}{|c|c|c|c|c|c|c|c|c|c|c|c|c|c|c|c|c|c|c|}
\hline \multicolumn{19}{|c|}{ Continued } \\
\hline $\begin{array}{c}\text { Gfkf- } \\
\text { prevrenune }\end{array}$ & & & & 0.034 & 0.114 & $0.104^{*}$ & & & & 0.005 & 0.157 & 0.053 & & & & 1.431 & $-21.25^{*}$ & 4.967 \\
\hline \multirow[t]{2}{*}{$\begin{array}{c}\text { Gfks- } \\
\text { prevrenune }\end{array}$} & & & & -0.046 & -0.120 & -0.073 & & & & -0.057 & -0.337 & 0.082 & & & & -1.882 & $-25.43^{*}$ & 5.977 \\
\hline & & & & -0.057 & -0.158 & -0.093 & & & & -0.283 & -0.515 & -0.442 & & & & -4.507 & -13.680 & -7.490 \\
\hline \multirow[t]{2}{*}{$\begin{array}{l}\text { gfgskfprevre- } \\
\text { nune }\end{array}$} & & & & -0.043 & -0.040 & -0.004 & & & & -0.026 & 0.012 & -0.099 & & & & 2.474 & 6.094 & -2.465 \\
\hline & & & & -0.038 & -0.065 & -0.039 & & & & -0.176 & -0.263 & -0.212 & & & & -3.028 & -6.218 & -3.297 \\
\hline \multirow[t]{2}{*}{$\begin{array}{l}\text { gfkfksprevre- } \\
\text { nune }\end{array}$} & & & & -0.006 & 0.148 & -0.051 & & & & 0.149 & -0.319 & 0.093 & & & & 2.147 & 7.379 & 0.369 \\
\hline & & & & -0.055 & -0.166 & -0.072 & & & & -0.283 & -0.553 & -0.401 & & & & -4.383 & -14.540 & -6.038 \\
\hline $\begin{array}{l}\text { gfgskfkspre- } \\
\text { vrenune }\end{array}$ & & & & -0.721 & 0.000 & -0.703 & & & & -2.882 & 0.000 & -3.027 & & & & -56.870 & 0.000 & -54.100 \\
\hline \multirow[t]{2}{*}{ Constant } & $0.0912^{* * *}$ & $0.158^{* * *}$ & $0.0522^{* * *}$ & $0.0901^{* * *}$ & $0.161^{* * *}$ & $0.0542^{* * *}$ & $0.747^{* * *}$ & $0.144^{* *}$ & $0.412^{* * *}$ & $0.748^{* * *}$ & $0.126^{*}$ & $0.412^{* * *}$ & $7.428^{* * *}$ & $6.112^{* * *}$ & $3.044^{* *}$ & $7.653^{* * *}$ & $5.059^{* * *}$ & $3.105^{* *}$ \\
\hline & -0.013 & -0.021 & -0.017 & -0.013 & -0.021 & -0.017 & -0.052 & -0.071 & -0.076 & -0.053 & -0.071 & -0.076 & -1.048 & -1.910 & -1.336 & -0.907 & -1.751 & -1.218 \\
\hline $\mathrm{Ob}$ & 4600 & 1117 & 2138 & 4600 & 1117 & 2138 & 4575 & 1092 & 2138 & 4575 & 1092 & 2138 & 4465 & 1075 & 2082 & 4465 & 1075 & 2082 \\
\hline No.stkcd & 717 & 601 & 716 & 717 & 601 & 716 & 717 & 586 & 716 & 717 & 586 & 716 & 717 & 587 & 707 & 717 & 587 & 707 \\
\hline
\end{tabular}

Consistent with Hypothesis 1a, the ks involvement is proportional to herfindahl_10 (see Table 2), and socioemotional wealth will gain benefits from the increase of herfindahl_10. Although some of the variables are not outstanding, the coefficients of the 4 out of 8 types of GUANXI differentiated from each other (see Table 2). This is unanimous with Hypothesis $\mathbf{1 b}$. Per the influence that family involvement imposed on shrhfdm, under remarkable situations, various family members' involvement contributes to the dispersion. In Table 2, only the gs is negative with vc in the period of PC (but it is not significant). The results confirm that the effect of gf is not a like that of ks in socioemotional wealth protecting behaviors at the lamination of firm governance, and that in accordance with Hypothesis 3, the crisis can change the family members' action to protect socioemotional wealth (by comparing the LC data regressions to the PC data regressions).

\subsection{External Environment Change, Family Involvement and Firm Governance}

For the improvement of the external environment change (Hypothesis 2), we find that during the period of P/LC, the higher level the provrevenue, the greater theherfindahl_10 $(p<0.01)$; during the period of $\mathrm{P}$, the higher level the provrevenue, the smaller the shrhfdm $(p<0.01)$; during the period of LC, the higher level the provrevenue, the greater the shrhfdm $(p<0.1)$, and the effect of provrevenue on vc is not considerable. When taking the variable of provrevenue into models, the changes of ks affect not only coefficients but also the significances. This result suggests that family involvement does affect the family firm governance in the term of the shareholding structure which is closely tied to socioemotional wealth. Finally, we draw the conclusion that the amelioration of the external environment change is positive with socioemotional wealth protection.

In order to test whether it is a substitute or complementary relationship between external environment change and family involvement, we hinges on the sign and significance of coefficients for family firm governance (herfindahl_10/shrhfdm/vc). The results (which have been declared in Table 4) present that only few interaction items are significant $(p<0.1)$. Most negative coefficients imply a substitute relationship in which higher provrevenue predicts less family involvement. Just as all of the coefficients are not significant, we have to accept the argument that the external environment change improvement has the function to adjust family members' behavior in socioemotional wealth protection (Hypothesis 3), yet we cannot confirm a substitute relationship between external environment change and family involvement. Although this paper does not depict an exact relationship between institutional environment and family involvement, it interrogates the previous theories, both $\mathrm{AC}$ and RBV. 
In empirical tests, we also investigated the interaction between family involvement and external environment change, finding that even some original variable symbols have changed; they are still not that considerable. Additionally, we did some inspections to test the rubustness of the results. First of all, we get the similar results by carrying out regression test, which is done through the control ship of heteroskedasticity and autocorrelation. Next, we build a marketization index (the ratio of private-listed enterprises to all local enterprises) to conduct the regression test, and the results are basically the same. Finally, we examine different family members' behaviors during the period of IC, finding the result similar with these during the period of LC. The difference is that the greater impact family involvement imposed on shrhfdm, the more prominent coefficients are.

\section{Discussion and Conclusion}

In the field of strategic management, most empirical work is based on AC or stewardship. Contrary to this existing path, our empirical study is in the view of socioemotional wealth. Considering that preserving socioemotional wealth is the key motivation of family involvement and that firm governance is closely linked to socioemotional wealth protection, we eventually draw a conclusion that the family involvement has the function to affect firm governance. Before economic crisis, the impact family involvements imposed on family firm governance mainly focus on family enterprise shareholding ratios from different groups and separation between ownership and control rights. This phenomenon, in certain ways, indicates that the involvement of family members may cause the disturbance of family members. After economic crisis, shareholding ratios, to some extent, still carry some weight, but some influence wakens the awareness of threat within some family members after the crisis.

We also find that external environment change changes can affect socioemotional wealth via impact imposed on family involvement [1]. This point of view helps family involvement to preserve socioemotional wealth as the amelioration of institutional environment goes on, but weakens family business control ship from one single family. Also, when the family enterprises are being threatened, alertness from family members will be aroused, thus arousal of sense of crisis contributes to socioemotional wealth preservation. Furthermore, we find that when the survival of family enterprises is under threat, strength from the first generation should not be underestimated while the strength from the second generation seems somewhat fragile. This may be explained that on one side, the strength from second generation is not vigorous enough; on the other side, many second generation themselves are united with their parents.

Although our study utilizes cross-sectional data and time data, subdivides family involvement in internal family enterprise, and investigates different members' attitude towards socioemotional wealth preservation before and after the economic crisis. In the empirical test, some key variables, which affect family corporate governance variables, are still not that significant. We also look into the effect of institutional environment on family involvement, but the interaction model is not that striking. Ultimately, our study is based on the theory of socioemotional wealth, and the empirical results back up Millers' opinion. This is merely a beginning. In our study, we only inspect the impact on family business governance behavior considering family involvement, while the impact on daily activities of family enterprises still needs further verification. Furthermore, the measurement of socioemotional wealth and its allocation among different family members, and different family members' attitudes and behaviors in different periods, will be the direction of our future efforts.

\section{References}

[1] Le Breton-Miller, L. and Miller, D. (2013) Socioemotional Wealth across the Family Firm Life Cycle: A Commentary on "Family Business Survival and the Role of Boards”. Entrepreneurship Theory and Practice, 37, 1391-1397. http://dx.doi.org/10.1111/etap.12072

[2] Miller, D., Le Breton-Miller, I. and Lester, R.H. (2013) Family Firm Governance, Strategic Conformity, and Performance: Institutional vs. Strategic Perspectives. Organization Science, 24, 189-209. http://dx.doi.org/10.1287/orsc.1110.0728

[3] Gomez-Mejia, L.R., Makri, M. and Kintana, M.L. (2010) Diversification Decisions in Family-Controlled Firms. Journal of Management Studies, 47, 223-252. http://dx.doi.org/10.1111/j.1467-6486.2009.00889.x

[4] La Porta, R., Lopez-de-Silanes, F., Shleifer, A. and Vishny, R. (2002) Investor Protection and Corporate Valuation. Journal of Finance, 57, 1147-1170. http://dx.doi.org/10.1111/1540-6261.00457

[5] (2012) Family, Marketization and Entrepreneurial Business Relationship Network Transaction Costs. Nankai Man- 
agement Review.

[6] McConaugby, D.L., Matthews, C.H. and Fialko, A.S. (2001) Founding Family Controlled Firms: Performance, Risk, and Value. Journal of Small Business Management, 39, 31-49. http://dx.doi.org/10.1111/0447-2778.00004

[7] Chen, H.L. and Hsu, W.T. (2009) Family Ownership, Board Independence, and R\&D Investment. Family Business Review, 22, 347-362. http://dx.doi.org/10.1177/0894486509341062

[8] Van Essen, M., van Oosterhout, J.H. and Carney, M. (2012) Corporate Boards and the Performance of Asian Firms: A Meta-Analysis. Asia Pacific Journal of Management, 29, 873-905. http://dx.doi.org/10.1007/s10490-011-9269-1

[9] Chrisman, J.J. and Patel, P.C. (2012) Variations in R\&D Investments of Family and Nonfamily Firms: Behavioral Agency and Myopic Loss Aversion Perspectives. Academy of Management Journal, 55, 976-997. http://dx.doi.org/10.5465/amj.2011.0211

[10] Mundlak, Y. (1978) On the Pooling of Time Series and Cross Section Data. Econometrica, 46, 69-85. http://dx.doi.org/10.2307/1913646 